\title{
Concomitant fracture of the coracoid process following acromioclavicular joint dislocation
}

\section{Dear Editor,}

Isolated acromioclavicular joint (ACJ) dislocations occur in $9 \%$ of shoulder injuries. However, ACJ dislocations with concomitant fracture of the coracoid process are rare. We describe a case of ACJ dislocation in detail, and review all 57 cases reported in the literature for clinical and radiographic characteristics; mechanism of injury; treatment plans; and overall outcomes in relation to such injuries.

A 53-year-old right-handed man missed the steps of a staircase and fell, sustaining a left shoulder injury. The man had a previous medical history of chronic kidney disease, hypertension, ischaemic heart disease, type 2 diabetes mellitus as well as hyperlipidaemia. He was a non-smoker and does not consume alcohol.

He presented to the emergency department 9 days after the accident, complaining of pain and limited mobility of his left shoulder. On examination, he had tenderness, swelling and a painful step deformity at the ACJ, with an active range of motion (ROM) limited to 90 degrees of abduction. There were no neurological symptoms. During subsequent orthopaedic consultation, post-trauma left shoulder radiographs showed ACJ dislocation and an Ogawa ${ }^{1}$ Type I coracoid process fracture. When compared with the contralateral side, the displacement of the left coracoclavicular (CC) distance was not significant. Left shoulder magnetic resonance imaging (MRI) confirmed a mildly displaced avulsion fracture through the base of the coracoid process; torn AC ligament; and sprained but intact $\mathrm{CC}$ ligament (Fig. 1). A small posterosuperior glenoid labral tear was seen at the 11 o'clock position. The coracoid fracture was not demonstrated to be close to neurovascular structures on MRI.

The patient elected for conservative management, given his significant cardiovascular comorbidities and relatively low functional demands. Treatment with an arm-sling was instituted. A month later, the patient experienced reduced pain, but active ROM remained limited at 90 degrees of abduction and ACJ step deformity persisted. He underwent physiotherapy for passive ROM exercises with subsequent progression to active ROM and strengthening exercises. At 2 months follow-up, ROM improved to 140 degrees forward flexion and 100 degrees abduction. The patient's pain was minimal-3 out of 10 on the visual analogue scale for pain. The patient was then discharged from physiotherapy for continued home exercise. Interval radiographs taken 2 months after the initial dislocation revealed a stable left ACJ dislocation with mild superior displacement of the coracoid process. At a final review 2 years post-injury, although a small palpable bump was present, the patient was free of pain, with full ROM (forward flexion and abduction 170 degrees; external rotation 60 degrees; internal rotation to the level of T10). He declined further imaging as he had been clinically well and was discharged.

The ACJ and coracoid process form an integral part of the superior shoulder suspensory complex (SSSC), which includes the distal clavicle, acromion, glenoid and $\mathrm{CC}$ ligaments, ${ }^{2}$ that contributes to biomechanical stability. Therein lies the importance of recognising ACJ dislocations with concomitant coracoid fractures, because they represent a double disruption of the SSSC to weaken biomechanical stability significantly.

Three main mechanisms of ACJ dislocations with concomitant coracoid process fractures were described by DiPaolo et al. ${ }^{3}$ The second mechanism, involving a direct blow to the ACJ, best describes our patient's injury following his fall. The traumatic force pushes the acromion caudad while the coracoid process is pulled by the CC ligament with the clavicle cephalad, avulsing it from its base.

ACJ injuries are typically classified based on the Rockwood 6-type classification system. In spite of the normal radiographic CC distance, our patient's case was likely a Rockwood Type III variant. The broken coracoid process was displaced superiorly and the ACJ was dislocated with superior displacement of the clavicle, resembling a Rockwood Type III in principle where both acromioclavicular and $\mathrm{CC}$ ligaments are ruptured. We also observed the concomitant Ogawa Type I coracoid fracture, ${ }^{1}$ as the fracture occurred at the base of the coracoid process (Fig. 1). This association with an Ogawa type I coracoid fracture has been reported in more than $50 \%$ of ACJ injuries associated with coracoid fractures. ${ }^{3}$

We summarise our case presentation and review all 57 cases reported in the literature (Table 1). Kose et al. reported 2 cases and reviewed 46 cases in the literature in $2015 .{ }^{4}$ There were 9 additional cases reported after $2015 .^{5-12}$ 


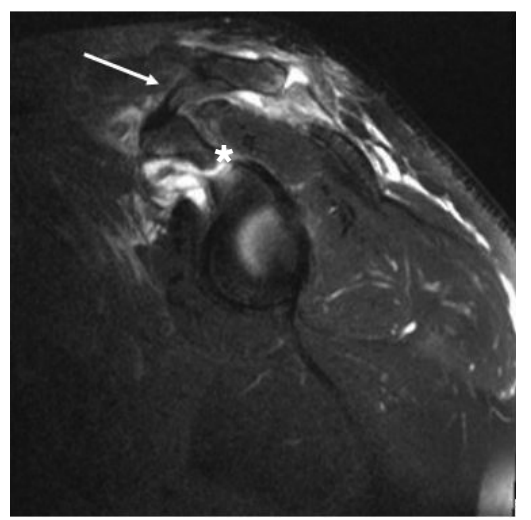

Fig. 1. Sagittal T2-weighted MRI of the left shoulder 10 days post-injury, demonstrating a mildly superiorly displaced avulsion fracture through base of the coracoid process; torn AC ligament; and sprained coracoclavicular ligament. White arrow indicates intact coracoclavicular ligament; asterisk shows site of coracoid fracture.
Half $(47.3 \%)$ of the documented cases were managed completely by conservative means, reflecting the ongoing debate on conservative versus surgical approaches for such fractures. Given the rarity of case reports in the literature, and that most surgeons have treated a few cases at most with varying surgical techniques and indications, statistical analysis of the cases was not feasible. However, functional outcomes for both conservative and surgical management of the cases have largely been good and excellent.

Surgery may be indicated for a few reasons, such as: (1) young patients requiring significant upper limb strength for work or hobbies; (2) neurovascular compromise; (3) open fractures; and (4) symptomatic non-union. However, conservative treatment may be preferred due to the peri-operative anaesthetic and procedural risks,

Table 1. Outcomes of published cases ${ }^{\mathrm{a}}$ of ACJ dislocation associated with coracoid process fracture, including the current case presentation

\begin{tabular}{|c|c|c|c|c|}
\hline \multicolumn{5}{|c|}{ Management of coracoid process fracture $(n=55)$} \\
\hline Outcome & Excellent & Good & Poor & NR \\
\hline Conservative treatment & 18 & 9 & 1 & 2 \\
\hline \multicolumn{5}{|l|}{ Surgical treatment } \\
\hline Open reduction and internal fixation & 14 & 3 & & 2 \\
\hline Dewar-Barrington procedure $^{\mathrm{b}}$ & & 3 & & \\
\hline Kirschner wire & 1 & & & \\
\hline Non-specific & 2 & & & \\
\hline \multicolumn{5}{|c|}{ Management of ACJ dislocation $(n=57)$} \\
\hline Outcome & Excellent & Good & Poor & NR \\
\hline Conservative treatment & 14 & 9 & 1 & 2 \\
\hline \multicolumn{5}{|l|}{ Surgical treatment } \\
\hline Coracoclavicular ligament repair & & & 1 & \\
\hline Kirschner wire & 7 & 2 & 1 & \\
\hline Tension-band wiring & & 1 & & \\
\hline Screw fixation & 5 & & & 1 \\
\hline Hook plate fixation & 3 & 1 & & \\
\hline Dewar-Barrington procedure ${ }^{\mathrm{b}}$ & & 3 & & \\
\hline Modified Neviaser's procedure ${ }^{\mathrm{c}}$ & & 1 & & \\
\hline Non-specific & & & & 1 \\
\hline Non-specific & 4 & & & \\
\hline
\end{tabular}

ACJ: acromioclavicular joint; NR: not recorded

${ }^{a}$ Cases in REFERENCES numbers 3-12

${ }^{\mathrm{b}}$ Dewar-Barrington procedure: A method of transferring the conjoint tendon to the lateral clavicle for the treatment of high-grade AC dislocations to stabilise the clavicular strut and maintain anatomical apposition of the acromioclavicular and coracoclavicular ligaments for recovery

' Modified Neviaser's procedure: Reduction of a complete ACJ dislocation by surgical transfer of the coracoacromial ligament, along with a piece of bone detached from the acromial end, to the distal end of the clavicle and fixed with a cancellous screw 
and we recommend that each case be considered individually before arriving at a treatment decision. Lastly, depending on the fracture morphology and injury mechanism, further imaging with computed tomography may be considered for further evaluation.

\section{REFERENCES}

1. Ogawa K, Ikegami H, Takeda T, et al. Defining impairment and treatment of subacute and chronic fractures of the coracoid process. $\mathrm{J}$ Trauma 2009;67:1040-5.

2. Gonçalves MHL, Garcia Jr JC. A comprehensive review of triple disruptions of the superior shoulder suspensory complex and case report. Acta Shoulder and Elbow Surg 2016;1:56-61.

3. DiPaola M, Marchetto P. Coracoid process fracture with acromioclavicular joint separation in an American football player: a case report and literature review. Am J Orthop (Belle Mead NJ) 2009;38:37-40.

4. Kose O, Canbora K, Guler F, et al. Acromioclavicular dislocation associated with coracoid process fracture: Report of two cases and review of the literature. Case Rep Orthop 2015;2015:858969.

5. Dunn JC, Waterman BR. Successful nonoperative management of coracoid fracture associated with suture-button fixation of acromioclavicular separation. Mil Med 2015;180:e138-41.

6. Nakamura Y, Gotoh M, Mitsui Y, et al. A case of acromioclavicular joint dislocation associated with coracoid process fracture. Kurume Med J 2015;61:77-9.

7. Sharma N, Mandloi A, Agrawal A, et al. Acromioclavicular joint dislocation with ipsilateral mid third clavicle, mid shaft humerus and coracoid process fracture-a case report. J Orthop Case Rep 2016;6:24-7.
8. Morioka T, Ogawa K, Takahashi M. Avulsion fracture of the coracoid process at the coracoclavicular ligament insertion: a report of three cases. Case Rep Orthop 2016;2016:1836070.

9. Lidgett T, Bate E, Pittock L. Superior shoulder suspensory complex fracture dislocation case report. Radiography (Lond) 2017;23:e68-71

10. Cabanas J, Jennart H, Leclercq G, et al. 74-year-old man with a complex acromio-clavicular disjunction. Rev Med Brux 2018; 39:50-4.

11. Duinslaeger E, Kirby JH, Viljoen JT, et al. The forgotten coracoid: A case report of a coracoid fracture in a male cyclist. S Afr J Sports Med 2016;29:1-2.

12. Metwaly RG, Edres K. Biplanar fixation of acromio-clavicular joint dislocation associated with coracoid process fracture: Case report. Trauma Case Rep 2018;15:4-7.

Glen Zi Qiang Liau ${ }^{1}$ MMed (Ortho),

Sean Kean Ann Phua ${ }^{2}$ MBBS (S'pore), Tianpei Li ${ }^{2}$ MBBS (S'pore), Kwan Yi Yap ${ }^{2}$, Rachel Wei Ling $\underline{\text { Teo }}^{2}$,

Ruben Manohara ${ }^{1}$ FRCS (Ortho)

${ }^{1}$ Department of Orthopaedic Surgery, National University Hospital, Singapore ${ }^{2}$ Yong Loo Lin School of Medicine, National University of Singapore, Singapore

Correspondence: Dr Glen Zi Qiang Liau, Department of Orthopaedic Surgery, National University Hospital, NUHS Tower Block, Level 10, 1E Kent Ridge Road, Singapore 119228. Email: glen_liau@nuhs.edu.sg 